\title{
Las luchas contra la contaminación: de la autodefensa a la recreación de la democracia
}

\author{
Cecilia Carrizo \\ Instituto de Investigación y Formación en Administración Pública,Universidad \\ Nacional de Córdoba, Córdoba, Argentina. Email: ccarrizo@iifap.unc.edu.ar

\section{Mauricio Berger} \\ Instituto de Investigación y Formación en Administración Pública. Consejo \\ Nacional de Investigaciones Científicas y Técnicas. \\ Email: mauricioberger@conicet.gov.ar
}

Resumen: Nuestro abordaje de las luchas contra la contaminación es político-institucional y tiene como punto de partida nuestra participación en el reclamo a las instituciones democráticas por el reconocimiento y garantía de la vida, la salud y el ambiente como derechos. Ante las consecuencias de proyectos megamineros, la agricultura transgénica, el desmonte del bosque nativo, entre otros; las luchas develan los específicos problemas de las instituciones de la república para cumplir los compromisos constitucionales. También promueven la reflexión e invocan la creatividad respecto a formas de articulación alternativas entre ejercicio de derechos, representación, ley y justicia; recuperando los aportes de la imaginación y la práctica ambiental para hacer frente al conflicto y la complejidad. En este marco, en lo que respecta a los desarrollos teóricos, consideramos un aporte contribuir con la reformulación del concepto de ciudadanía y de soberanía popular que se vienen realizando desde el pensamiento político verde y la teoría democrática como claves para la recreación de un sentido de la democracia que haga justicia con los afectados.

Palabras clave: luchas ciudadanas, derechos, ambientalismo, República, soberanía popular

\section{The struggles against pollution: from self defense to recreation of democracy}

\begin{abstract}
Our approach to the struggles against environmental pollution is political- institutional, and is related to our participation with our co-citizens in the claim to democratic institutions for recognition and guarantees of life, health and enviroment as rights. Facing the consequences of large- scale mining, transgenic agriculture, the cutting down of native forests, among others, the struggles reveal the specific problems of the institutions of the republic to fullfill its constitutional commitments. Also they promote reflexivity and creativity about alternative forms of articulation between exercise of rights, representation, law and justice. In doing so they recover the contributions from the environmental imaginary and practice in order to deal with conflict and complexity. Within this frame, we propose the theoretical contributions made by the green political thought and the democratic theory as key elements to the reformulation of a sense of democracy that makes
\end{abstract}


justice to the affected peoples.

Key words: citizens struggles, rights, environmentalism, Republic, popular sovereignity

\section{As lutas contra a poluição: da autodefesa a recreação da democracia}

Resumo: A nossa abordagem das lutas contra a poluição é políticoinstitucional e tem como ponto de partida nossa participação na demanda às instituições democráticas pelo reconhecimento e garantia da vida, a saúde eo meio ambiente como direitos. Diante as conseqüências dos projetos da mega-mineração, da agricultura transgênica, da tala de florestas nativas, entre outros, as lutas revelam os problemas específicos das instituições da República para cumprir os compromissos constitucionais. Além disso, se promove a reflexão ea criatividade com respeito às formas alternativas de articulação entre o exercício dos direitos, a representação, a lei ea justiça, recuperando as contribuições da imaginação e da prática ambiental para lidar com o conflito e a complexidade. Neste contexto, em relação aos desenvolvimentos teóricos, consideramos que este artigo contribui para a reformulação do conceito de cidadania e da soberania popular que está sendo feito desde o pensamento político verde ea teoria democrática, como eixos para recriar um senso de democracia que faz justiça às vítimas. popular.

Palavras-chave: lutas cívicas, direitos, ambientalismo, República, soberania

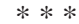

"En el caso nuestro, se han violado los derechos humanos y lo que nosotros estamos pidiendo es un derecho a la salud, a la vida y a un medio ambiente sano, que son prácticamente, si vos te das cuenta, un derecho que tendríamos que tener todos y ahora no lo tenemos. Es algo intransferible el derecho a la vida y violar ese derecho que es un derecho humano hace mal a todo, han pisoteado lo más sagrado de una persona.

Ellos con las fumigaciones, nos han fumigado con avionetas, no les importó la gente, nadie fue capaz de decir: No, hay un barrio cerca... no,

si no salía la gente, si no salíamos nosotros a pelear esto todavía lo seguirían haciendo. Se frenaron gracias a la pelea. La organización surgió

porque tuvimos que defendernos de algo que nos estaba dañando...”.

(Madres de Barrio Ituzaingó Anexo, Córdoba, Argentina).

Intentamos desde Autoconvocados generar un espacio abierto a la Comunidad y capacitarnos tod@s en la normativa legal vigente y exigir que se ponga en "real vigencia" las Ordenanzas Municipales $N^{\circ} 30 / 07$ y

13/08 bis. La primera declara a Cafayate como "MUNICIPIO NO

TÓXICO Y AMBIENTALMENTE SUSTENTABLE". La segunda "PROHÍBE EL TRÁNSITO POR CAFAYATE DE CAMIONES DE 
GRAN PORTE Y LOS QUE TRANSPORTAN SUSTANCIAS PELIGROSAS". Nos hemos reunido reiteradamente con el nuevo Intendente, los comisarios tanto de la seccional Cafayate como de la Regional y del

911, director de Tránsito de Cafayate y Concejales de manera conjunta para establecer pautas y puntos específicos en cuanto a la aplicación y funcionamiento de ambas Ordenanzas. Recordamos a los cumpas que, en cuanto se apliquen, ya NO PODRÁN TRANSITAR DESDE EL NORTE HACIA EL SUR Y VICERVERSA NINGÚN CAMIÓN CON INSUMOS DESTINO A MINERA ALUMBRERA Y AGUA RICA (o a cualquier otra). Es por lo que venimos luchando desde hace años, con denuncias de por medio a los Funcionarios Públicos por INCUMPLIMIENTO A SUS DEBERES y, también, por lo que hemos sido reprimidos y perseguidos. (Autoconvocados del Valle Calchaquí-Cafayate-Salta,

Argentina).

"Presentamos este proyecto de ordenanza por INICIATIVA POPULAR, como nos faculta la Ley Provincial No 8102 en sus artículos 33, 63, 146, 147, 148 y 149, debido a que ningún bloque político con representantes en éste Honorable Consejo Deliberante lo ha hecho antes. Pretendemos con ésta propuesta ejercer nuestro derecho democrático, contemplado en nuestros valores civiles como pueblo libre y soberano, y por el derecho a

la salud de todo ciudadano, generando una ZONA DE RESGUARDO

AMBIENTAL. Para nuestra realidad, la de los vecinos y las vecinas de ésta ciudad, la problemática de la afección a nuestra salud por plaguicidas usados en la actividad agrícola, es una urgencia. Que seamos los vecinos y las vecinas quienes ejerzamos la participación política directa en nuestra ciudad, a través de ésta herramienta legal que nos provee nuestro derecho, es el mejor indicador de la salubridad de nuestra democracia”. (Fundamen-

tos Ordenanza Creación Zona de Resguardo Ambiental ciudad de Oncativo, 22 de marzo de 2010. Vecinos Autoconvocados de Oncativo, Provincia de Córdoba, Argentina).

\section{Introducción}

Nuestro abordaje de las luchas contra la contaminación es políticoinstitucional y tiene como punto de partida nuestra participación, junto a nuestros conciudadanos, en los procesos concretos de movilización ciudadana -por fuera de las instituciones de representación- desde los cuales se reclama a las instituciones democráticas por el reconocimiento y garantía de la vida, la salud y el ambiente como derechos. En los últimos 10 años en Argentina y ante el avance de proyectos megamineros, la agricultura 
transgénica, el desmonte del bosque nativo, las luchas ciudadanas trabajando en red con otras luchas en países vecinos, develan los específicos problemas de las instituciones de la república para cumplir los compromisos constitucionales. Por otro lado, hacen reflexivo el concepto de democracia como autoorganización y autolegislación de la ciudadanía, recuperando los aportes de la imaginación y la práctica ambiental para hacer frente al conflicto y la complejidad, construyendo solidaridades reales e instituciones en el espacio público y estatal.

Ante las dificultades de las luchas para sostener y profundizar la autoorganización y resistir la ofensiva disciplinadora y represiva del sistema político estatal y para-estatal, consideramos oportuno contribuir con desarrollos teóricos de la teoría democrática contemporánea que reformulan el concepto de ciudadanía y de soberanía popular desde las luchas ecológicas, feministas e indígenas en los últimos 40 años. Entendemos que el cuestionamiento al contenido liberal y homogeneizante de dichos conceptos, solapa y obstruye su rol clave en la recreación de un sentido de la democracia que haga justicia con los afectados.

Nuestro punto de partida de investigación son las concretas experiencias de luchas ciudadanas en situaciones de contaminación que tienen lugar en Argentina en la actualidad. Las mismas conforman redes provinciales (Paren de Fumigar, Asambleas Despierta), nacionales e internacionales (Unión de Asambleas Ciudadanas). Como investigadores, entendemos nuestra práctica como una contribución a un sentido de justicia que comprende a los afectados, los derechos y al ambiente, y se institucionaliza en el espacio público ciudadano y/o estatal generando garantías ${ }^{1}$. Posicionarnos en estas luchas persigue el objetivo de no constituirnos en extranjeros de los conflictos de nuestra época, esforzándonos para contribuir con las prácticas políticas defensivas y también prefiguradoras de una sociedad justa.

Inscribimos nuestra perspectiva de trabajo dentro de los aportes del pragmatismo para pensar los problemas públicos y la participación del investigador en los mismos. Concebimos, junto a Hilary Putnam, que "no hay un punto de vista del ojo de Dios desde el cual podamos decir que algunos de los enunciados que consideramos correctos y para los que ofrecemos argumentos razonables no son ni siquiera en principio susceptibles de "validez universal”, sino que sólo son susceptibles de algún tipo de razonabilidad relativa a la comunidad” (Putnam 2008). Recuperamos con ello el carácter esencialmente práctico de la razón en cuanto tal, afirmando que cuando un investigador participa con su producción de conocimiento en un conflicto donde está en juego el reconocimiento y la garantía de derechos, el posicionamiento "neutral" ya es un posicionamiento en situación. Desde este marco, utilizar la gramática de los derechos no es para nosotros la manifestación subordinada a una lógica "material” que explicaría los fenómenos, una narrativa de dominio. Por el contrario, es la posibilidad de hacer reflexivo el contexto intersubjetivo, contribuir a la definición del sentido de la situación en donde esté en juego nuestra propia comprensión compartida de la lucha. 
¿Qué cuestiones se ponen en juego cuando en el espacio público se invocan derechos? En primer lugar identificamos una práctica política ciudadana de interpelación a una asociación política sobre el sentido de justicia instituido, un reclamo de razón, de pertenencia, que pone en jaque la trama de discursos y prácticas que se arrogan la definición de la situación. Relevamos para ello documentos periodísticos y los generados desde las luchas y realizamos conversaciones con los protagonistas. En segundo lugar, el reclamo plantea la exigencia de un pronunciamiento. Que se diga una palabra que haga justicia forma parte del juego del lenguaje. Las instituciones, los funcionarios deben implementar algunos procedimientos, deben contribuir a reducir la incertidumbre, resolver el conflicto, reparar en lo posible el daño, en estos casos: individual, colectivo y al ambiente. Realizamos para identificar estas respuestas entrevistas a las autoridades de las instituciones interpeladas, análisis de documentos oficiales, entre otros. La aproximación pretende una reconstrucción de los acontecimientos que dé cuenta de los sentidos en disputa, las tensiones y, fundamentalmente, visibilice los problemas y las innovaciones que se desencadenan a partir de la acción ciudadana.

Relevamos desde la ciudadanía denuncias públicas, administrativas, judiciales individuales y colectivas; actos de desobediencia -cortes de ruta, tomas de edificios-, prácticas de acción directa - escraches (funas), declaraciones, elaboración de legislación defensiva (ordenanzas, leyes provinciales y nacionales), pedidos y/o realización de estudios, gestiones ante organismos internacionales -denuncias a la Corte Interamericana de Derechos Humanos y Tribunales éticos contra las corporaciones transnacionales-. Nuestro interés no es evaluar su novedad o tradición, ni develar la causalidad de este vasto repertorio de acciones, sino precisar los específicos obstáculos con los que se encuentran, así como los impactos que generan en la institucionalidad vigente. Las luchas no solo exigen la actualización de las instituciones sino que presionan por una institucionalidad nueva que efectivamente reconozca derechos e instituya garantías. Por otra parte desde la vivencia de las dificultades con el sisstema político-representativo, la ciudadanía invoca cada vez con mayor convicción no solo sus derechos sino el ejercicio a la autodeterminación sobre las decisiones que afectan sus vidas y formas de vida. Son estos efectos simultáneos los que denominamos pasaje de la autodefensa a la recreación de la democracia.

Estrechamente ligado a dicho pasaje, nos interesa visibilizar, por un lado, los aportes de la imaginación y la práctica ambiental que incorporan las luchas para hacer frente al conflicto y la complejidad de los problemas ambientales. Por otro lado, avanzamos en desarrollos teóricos que contribuyen a la reformulación del concepto de ciudadanía y de soberanía popular que se vienen realizando desde el pensamiento político verde y la teoría democrática. En el contexto de las luchas, el cuestionamiento al contenido liberal y homogenizante de dichos conceptos, solapa y obstruye su rol clave en la recreación de un sentido de la democracia que haga justicia con los afectados. El valor de una vida es comprendido por el discurso de los 
derechos en disputa con el utilitarismo desarrollista, mientas que el reconocimiento de la diversidad de saberes, racionalidades y voluntades en las luchas resiste a la monopolización de la representación partidaria.

\section{Problemas de las instituciones de la república}

Los reclamos por derechos en situaciones de contaminación con efectos sobre la salud de la ciudadanía y el ambiente interpelan a los Poderes Públicos de la república, al lenguaje instituido por la Constitución y las leyes. Sistematizamos entonces los problemas visualizados en base a la actuación del Poder Legislativo, Ejecutivo y Judicial.

Existen dificultades para que el Poder Legislativo ejerza el poder de policía legislativo (Ferrajoli 2000), es decir limite el ejercicio de los derechos individuales en pos de la salud pública y el interés general demandados desde las luchas. Especialmente este problema se evidencia Argentina en relación a la legislación nacional claramente pro-minera vigente desde los 90. También en la ausencia de legislación nacional que fije presupuestos mínimos para la regulación del uso de agrotóxicos², así como la desactualización de los parámetros y marcos normativos para el control de la calidad del agua, entre los más destacables.

Esta dificultad es tanto ideológica, luego de años de neoliberalismo, como política-institucional. La conformación y el funcionamiento de este poder del estado evidencia el pasaje de un sesgo sistemático del sistema representativo a favor de los intereses empresarios, a su misma conformación por empresarios y agentes de las empresas, pasaje del que da cuenta el concepto de capital-parlamentarismo (Negri 2000). Ello ha dado lugar a acciones ciudadanas que invocando "conflicto de interés", solicitan la inhabilitación de representantes en el tratamiento de leyes donde están directamente involucrados por ser ellos mismos empresarios de los agronegocios. Tal el caso de sucedido en la provincia de Santa Fé en relación al pedido de tratamiento legislativo de la reforma provincial de la ley de productos fitosanitarios propuesta por la ciudadanía. La misma pretende, entre otros puntos, la prohibición de las fumigaciones áreas y la generación de zonas de resguardo que protejan a las poblaciones, escuelas rurales y cursos de agua (Manessi 2012).

Otro de los problemas a enfrentar tiene que ver con las nuevas modalidades de la gobernabilidad capitalista. Si bien la legislación ambiental de los 80, 90 y hasta mediados de la primera década de este siglo instituía medidas de comando y control sobre las actividades contaminantes, la nueva legislación promueve distintas modalidades de des-responsabilización del estado y privatización del control en manos de las mismas empresas, promoviendo una retirada de la temática ambiental de la esfera política por declaraciones "ambientalmente responsables" de las empresas (Acselrad 2012). También en este sentido sucede la institucionalización de políticas proactivas para la introducción de tecnologías limpias con financiamiento 
público (Carrizo y Berger 2010) y mecanismos de mercado, supuestamente capaces de dar un tratamiento técnicamente adecuado a los procesos de producción contaminantes mediante la puesta en valor de los servicios ambientales (Carrizo 2011).

Una mención especial merece la Ley de Glaciares y la Ley de Bosques en Argentina. Si bien ambas incorporan importantes medidas para la protección, la falta del ejercicio de control sobre el Ejecutivo - que también es función legislativa- lleva a una débil implementación sobre el territorio. A ello se suma la judicialización para evitar su aplicación por parte de algunas provincias, entre las que se destaca la de San Juan, cuando no a su inversión de sentido por las legislaturas provinciales. Tal el caso de la provincia de Córdoba, donde la ley de bosques provincial transforma el sentido de la ley nacional, de promover la preservación a promover su explotación "racional”.

En lo que respecta al Poder Ejecutivo, destacamos la ineficiencia de sus estructuras institucionales para ejercer la fuerza de ley -el poder de policía administrativo- para que funcionen como una trama de acciones garantizadoras de los derechos. Desmanteladas las estructuras tras las privatizaciones y mercantilizados los propios laboratorios aún estatales, la realización de controles y análisis es un déficit recurrente. En algunas provincias, tal el caso de la de Santa Fé, se está tratando de revertir esta situación con la compra de equipamientos y puesta en funcionamiento de un sistema de monitoreo de calidad del agua periódico a nivel provincial.

Otro problema es la preeminencia de criterios políticos por sobre criterios técnicos y jurídicos en las decisiones. Ello conlleva la superfluidad de las actuaciones precautorias y/o preventivas previstas que involucran al conocimiento técnico, como es el caso de los informes de impacto ambiental y la participación ciudadana. En lo que respecta a los criterios político-institucionales, el absoluto desconocimiento del federalismo, como es el caso del Ejecutivo avanzando por sobre competencias provinciales y/o locales aprobando proyectos de inversión. Tal el caso de la firma de convenios en donde se ceden territorios a empresas para la producción agropecuaria transgénica sin consulta a municipios y comunidades indígenas (Sodero Nievas 2012).

Finalmente, subrayamos un problema con efectos paralizantes de la acción política de la ciudadanía, la intervención disuasiva del Poder Ejecutivo sobre la defensa ecológica ejercida por la ciudadanía. La activación de "procedimientos clientelares" (distribución selectiva de planes sociales en territorio en lugar de reconocimiento e indemnización por el daño, ejercicio de violencia, entre otras), la denegación de identidad y/o razonabilidad, la criminalización de la protesta, la persecución y represión, estatal y para estatal (Machado 2012). Estas son prácticas habituales y en aumento en los cotidianos de las luchas. Los efectos de estas prácticas refuerzan relaciones de dominación. Intentan sistemáticamente desactivar las potencias que se componen en las luchas en situaciones de contaminación, haciendo de 
ellas un problema público. Para nosotros lo relevante es la tematización de la defensa de la vida y las formas de vida afectadas y/o amenazadas por el avance extractivista sobre el territorio y sobre relaciones sociales, despojando derechos y privatizando y contaminando bienes comunes.

En lo que respecta a las dificultades del Poder Judicial, señalamos como principal la distancia de la ciudadanía de la institución, el lenguaje y funcionamiento de la administración de justicia. También la desigual actuación de los principios ambientales por parte de las distintas jurisdicciones, provincias e incluso funcionarios ${ }^{3}$. Mientras la Corte Suprema avanza en la implementación de principios e instituciones del derecho ambiental, los Tribunales Superiores provinciales tienen una actuación dispar, llegando a plantear conflictos entre derechos a la propiedad y a la salud y el ambiente, y hasta la criminalización de la defensa ecológica. Más dispar aún es la actuación de jueces y fiscales y mínima la actuación de los defensores oficiales respecto a las víctimas de la contaminación. Una mención especial merece la inercia de conceptos y prácticas de otras ramas del derecho, tal el caso de la penal, para obstruir las investigaciones así como la ausencia de procedimientos y recursos humanos específicos y capacitados para llevarlas a cabo, lo que sumado al costo de los análisis y la impotencia para efectivizar el principio de contaminador paga, lleva a la parálisis de las causas. Finalmente, y para nada menor, otra dificultad constatada desde la investigación es la falta de cumplimiento de la sentencia, que se agrava incluso cuando el estado es el responsabilizado.

Identificar estos problemas nos permitió lograr una nueva comprensión de la situación y de nuestra posición como investigadores. Las luchan invocan un sentido de justicia, una serie de principios y procedimientos republicanos para la defensa de la vida, las formas de vida y el ambiente, pero estos mecanismos no están siendo eficaces. Complicidad estructural, corrupción, complejidad de los sistemas a desarrollar y sostener (de salud, de control, judicial, etc.), son factores que se suman y generan crecientes exigencias a la acción política y al ejercicio de la autodeterminación individual y pública sobre su presente y futuro.

\section{De los problemas a las alternativas en situaciones de contaminación}

Hacer conscientes las reglas interactivas de los acontecimientos, examinar los presupuestos de la organización institucional y su inefectividad respecto al reconocimiento y ejercicio de derechos, nos lleva como ciudadanos y como investigadores a preguntarnos por las posibilidades de recuperar su sentido fundante o desarrollar capacidades para su transformación. La desactivación de un trabajo de juridificación de la soberanía popular y de principios de justicia ambiental complejo- tanto a nivel intelectual como político-institucional- promueve la reflexión e invoca la creatividad respecto a formas de articulación alternativas entre ejercicio de derechos, representación, ley y justicia. 
Una primera línea de reflexiones tiene que ver con que las luchas ponen en evidencia los límites del monopolio de la representación por los partidos políticos y replantean como mínimo la necesidad de actualizar cuestiones de reconocimiento y representación de grupos sistemáticamente excluidos. ¿Cómo resolver las asimetrías presentes en las estructuras de representación, fundamentalmente para que sea escuchada la voz de los afectados?, ¿Desde el aprendizaje democrático podemos contribuir a la creación de nuevas mutualidades e instituciones para hacer frente a las nuevas y viejas desigualdades que se acumulan con la creciente mercantilización de los bienes comunes?.

Los desarrollos de la teoría política contemporánea en torno al concepto de justicia vienen contribuyendo a una ampliación de su definición: de la justicia como redistribución a la justicia como reconocimiento y también como representación (Honneth y Fraser 2006). En este sentido, una justicia democrática promueve una ampliación de la participación, otorgando centralidad al principio de intervención de los afectados. El análisis crítico de los procesos de participación real permite visualizar la despotenciación de la participación de los afectados, su dilución en mesas o espacios con otros actores tecnocráticos y corporativos o neocorporativos, cuando no su directa exclusión de los espacios generados a tal fin (Carrizo y Berger 2009). La propuesta para que esta participación sea efectiva, sostiene que son los afectados los que deben participar en la definición de los marcos de referencia del espacio político donde sus demandas pueden ser examinadas y resueltas. Por caso, en la definición de los niveles admitidos de contaminación, las luchas develan que éstos se deciden en organismos internacionales, más cerca de los lobbies de las corporaciones transnacionales que de las estructuras representativas de la ciudadanía y la vida concreta de los afectados. La posibilidad de enmarcar las situaciones desde estas experiencias puede modificar la escala local a la que generalmente se confina la participación y abrir otras posibilidades a la acción, como de hecho está sucediendo en las redes de afectados a nivel nacional y transnacional (Fraser 2008).

Otra línea de reflexión tiene como base los procesos de elaboración de ley por colectivos ciudadanos. La realización de proyectos de ley o de reforma a las leyes existentes tienen como objetivo regular o mejorar la regulación y el control sobre los procesos contaminantes, apelando al ejercicio del poder de policía legislativo (Ciuffolini 2012; Arnulphi 2012; Manessi, 2012; Tomasoni 2012). A nivel nacional se destaca en este sentido la ley de bosques y la ley de glaciares, ambas surgidas de la iniciativa ciudadana. En los casos provinciales se destacan desde la elaboración de leyes que prohíben la minería a gran escala con uso de sustancias tóxicas (Sede 2012), y proyectos de ley que establecen límites a las fumigaciones con agrotóxicos, entre otras; en los casos municipales, ordenanzas que declaran municipios no tóxicos, regulación del uso de suelo con criterios ambientales, etc.

También suceden intentos de legislación que no llegan a ser procesados por las legislaturas o son directamente adversos, en tanto se dirigen 
a derogar la legislación alcanzada por las luchas populares. Es en estos casos cuando se organizan desde la ciudadanía instancias de deliberación que se autodenominan Parlamentos. Tal el caso del Parlamento de los Pueblos (de la zona norte de Argentina) ${ }^{4}$ y el Parlamento Medioambiental de la Patagonia en alerta por minería y represas (con participación de ciudadanos de Chile y Argentina) $)^{5}$. Son estas experiencias las que anticipan otra institucionalidad ante la incapacidad de la vigente para articular una voluntad y decisiones colectivas que defiendan derechos y bienes comunes.

Finalmente nos interesa presentar una línea de reflexión que problematiza los procedimientos instituidos de la administración de justicia por utilizar el lenguaje de la conmensurabilidad. El resarcimiento y la recomposición tienen un costo. La crítica académica y su contribución a la configuración de otra justicia frente a la ineficacia de la instituida, ¿debe abandonar ese lenguaje o debe ampliarlo? En el arco de posiciones prevalece el planteo de modo antinómico.

Una justicia basada en la conmensurabilidad sería más de lo mismo; mientras que sostener el lenguaje de la inconmensurabilidad apostaría a una más radical resolución del conflicto (Martínez Allier 1994). Pero creemos legítimo preguntarnos: ¿qué acontece con lo dañado mientras esa enunciación cobra actualidad?, ¿Cuál es el destino de los reclamos de justicia concretos que se juegan en un vivir cotidiano? Desde estos interrogantes y desde la realidad de las vidas que merecen ser vividas a pesar de la enfermedad y el dolor, nos inclinamos por una posición inclusiva. La efectiva realización de la justicia reclama tanto la expedita resolución de los conflictos en el lenguaje instituido y el consecuente resarcimiento, como la construcción de un nuevo lenguaje que exprese una mutualidad comprensiva de la complejidad de los problemas ambientales. En este contexto, descalificar una resolución dentro del paradigma de la conmensurabilidad poco contribuye a una resolución emancipadora. Consideramos que tiene un efecto de desplazamiento de la crítica hacia un campo de debate académico en el que la práctica intelectual se aleja de los concretos problemas con los que se enfrentan los reclamos de justicia. Las líneas de reflexión señaladas desde concretos contextos intersubjetivos nos vinculan tanto teórica como prácticamente con la imaginación verde y democrática. En este sentido creemos que la investigación puede cooperar a la apropiación reflexiva de principios, pensamientos, instituciones del ambientalismo crítico así como a la apelación a la democracia como autodeterminación, a fin de profundizar el pasaje de la autodefensa a la recreación de la democracia.

\section{Algunos aportes del pensamiento ambiental para la democratización}

La denegación de razonabilidad hacia los ambientalistas no es una particularidad en Argentina. Desde diferentes latitudes, ámbitos y perspectivas teóricas y/o políticas, se ensayan discursos y prácticas que intentan poner en cuestión y hasta desactivar el núcleo motivacional del 
ambientalismo (Valdivieso 2005). La virulencia de este intento de exclusión política es proporcional al devenir de las luchas ambientales en un potente discurso público y prácticas que hacen del discurso ambiental una propuesta política reflexiva, acorde a la complejidad de nuestras sociedades y a la democratización de la misma.

En este marco, consideramos relevante para nuestro contexto intersubjetivo, realizar una reconstrucción de la imaginación ambiental y sus instituciones, con el propósito de rescatar aquellos aportes teóricoprácticos que disputan la fuerza movilizadora del discurso de los derechos para hacer frente a la mercantilización de la naturaleza y su forma de ley.

En Argentina, desde el último cuarto del siglo XIX y al interior mismo del desarrollo del modelo liberal, comienzan a regularse estatalmente los modos de adquisición y uso de los bienes de la naturaleza. Las medidas tendían a la preservación de algunos recursos, por ejemplo las leyes sobre arrendamientos y aparcerías rurales incluían disposiciones relacionadas con la conservación del suelo agrícola al igual que las normas referidas a los recursos mineros y forestales, aquellas para regular la caza y para reglamentar los usos de los recursos hídricos, entre las más relevantes. La intervención con fines de conservación de los recursos se profundiza a comienzos del siglo XX, no sin conflicto, con la concepción de la función social de la propiedad y del rol del estado en la restricción a la propiedad y a la mercantilización. Junto a la consideración del carácter inalienable e imprescriptible de los recursos naturales como bienes de la Nación, indubitable en la época, se promueven medidas que tienden al uso racional de los recursos tales como el de unidad económica de explotación, obligaciones de hacer respecto al combate de plagas y la veda presente en las leyes de caza, restricciones a la comercialización y tipificaciones de delitos (Zeballos 2000).

A nivel internacional cabe señalar la Primera Convención para la protección de la flora, de la fauna y de las bellezas naturales de los países de América que tiene lugar en Washington, en 1940. Por ella, los estados se comprometen a crear áreas con distinto tipo de protección para la salvaguarda de la flora, la fauna y las bellezas naturales ${ }^{6}$. A partir de la década del 60 acontece así una creciente juridificación tendiente a establecer compromisos compartidos de conservación de recursos vivos, humedales y mares, y reducir la comercialización para prevenir la contaminación con hidrocarburos y otras substancias.

Una mención especial en esta recuperación merece el Informe Meadows, "Los límites al crecimiento", lanzado por el Club de Roma en 1972. Sin dejar de reconocer las críticas al mismo, que subrayan que la "catástrofe malthusiana” anunciada desde dicho análisis no se debe al incremento geométrico de la población frente a los límites de los recursos, sino a la forma típica de explotación del capitalismo, la destrucción de sus bases de sustentación y la transferencia de costos a la sociedad ( $\mathrm{O}^{\prime}$ Connor 1994), es indudable que el mismo marcó un hito en el debate público sobre 
las interdependencias, las incertidumbres y los riesgos del modelo de desarrollo imperante. Otro hito en el mismo año, lo constituye la Declaración de las Naciones Unidas sobre el Medio Ambiente Humano. El propósito de ofrecer "un criterio y principios comunes que ofrezcan a los pueblos del mundo inspiración y guía para preservar y mejorar el medio humano” luego de 40 años, sigue insuflando discursos y prácticas de defensa del ambiente y criterios de política tan contundentes como inaplicados por las burocracias estatales denunciadas: el principio de precaución, el principio contaminador paga, el criterio de sustentablidad que implica considerar las generaciones futuras, la indemnización de las víctimas de la contaminación y su participación en el proceso de preparación de las decisiones que conciernen directamente a la reparación del daño a su salud y ambiente.

Nuevamente sin dejar de reconocer la validez de las críticas a la apropiación neoliberal del ambientalismo (Acselrad 2010), desde el seguimiento de la gramática de las luchas no quedan dudas de la relevancia y pertinencia de sus criterios y principios para la definición de una política (Hervé Espejo 2010) dirigida a transformar democráticamente las instituciones del sistema político oficial y el espacio público ciudadano a nivel nacional como internacional. Por otro lado, reconocer la historicidad de estos avances y la reconfiguración capitalista actual, nos alerta sobre la posibilidad concreta de que dejen de ser compromisos públicos y sean desmontados por la política de las transnacionales y los mismos estados.

De la denominada Cumbre de la Tierra, Conferencia de las Naciones Unidas realizada en Río de Janeiro en el año 1992, interesa destacar por un lado, la creciente normatización del comercio internacional y la aplicación de mecanismos de mercado para la regulación ambiental; por otro lado, la también creciente ampliación de un espacio público transnacional por la movilización ciudadana por fuera de las instituciones del estado. En este último aspecto también cabe destacar la cada vez más pronunciada divergencia entre la cumbre oficial y la cumbre de las organizaciones no estatales, que se realizan de forma simultánea como una práctica de denuncia y también de constitución de redes entre movimientos y organizaciones que ponen en común experiencias y proyectan estrategias conjuntas (Berger 2012).

La creación en 1995 de la Organización Mundial del Comercio introdujo nuevas fuentes de controversia, que desde Seattle en 1999 a Río+20 en el año 2012 fueron profundizándose. Las prácticas ambientalistas resisten a la configuración de un modelo de economía verde sostenido por los estados en torno a un pragmatismo de mercado y la búsqueda de soluciones paliativas bajo el imperativo de la cooperación consensualista (Acselard 2012).

La política de la resistencia no sólo sostiene la denuncia a las consecuencias mercantilizantes de la aplicación de las "herramientas inteligentes" del capitalismo verde, sino que avanza en la formulación de políticas a nivel local, nacional e internacional, como la declaración del Derecho Hu- 
mano al Agua, la declaración de los Derechos de la Madre Tierra/ Naturaleza, la Soberanía Alimentaria y otra serie de acciones comprendidas en el concepto de Justicia Climática. El eje de estas propuestas es revertir no sólo el carácter expropiador y contaminante del actual modelo de desarrollo, sino también instaurar criterios y principios que prefiguren lo nuevo articulando un amplísimo y heterogéneo frente de organizaciones sociales y políticas, un espacio público planetario desde las luchas ambientalistas más allá del estado y del mercado.

\section{Algunos aportes de la teoría política democrática La ciudadanía como esfera de acción}

Estas luchas han sido acompañadas por una creciente teorización política, en donde el concepto de ciudadanía es abordado tanto crítica como reconstructivamente a fin de superar los problemas individualistas de este concepto liberal e incorporar, a su vez, dimensiones que permitan visualizar las particularidades de las luchas ciudadanas actuales trascendiendo al liberalismo y al mismo estado-nación. En esta tarea ocupa un lugar clave la denuncia y propuesta respecto a los colectivos subrepresentados, la representación de las generaciones futuras y los seres no humanos y su consideración e inclusión en la toma de decisiones en el proceso democrático. Se impulsa así una ampliación de la participación política en distintas instituciones del espacio público estatal y ciudadano, superando la escala nacional y propugnando la actualización de los mismos conceptos de participación y representación políticas en el marco de construcción de un modelo democrático diferente (Fraser 2008; Schlosberg 2010).

En línea con estos procesos de teorización, la ciudadanía no sólo es comprendida como institución sino también como experimentación, como proceso de aprendizaje en la búsqueda de la justicia, desestabilizando las nociones establecidas.

Lejos de una visión estetizante, metafísica y romántica de la naturaleza, de una teoría hermética e insensible a lo contingente, la política y la práctica ambiental ciudadana hace suyos aspectos claves de la modernidad, como son los derechos humanos y el igualitarismo. Desde una diversidad creciente de posiciones de sujeto, los ciudadanos en sus luchas se apropian reflexivamente de la situación asumiendo el conflicto, la polémica, que rompe con el consenso utilitarista reinante (Sustein 2007) de la felicidad para el mayor número a la inalienabilidad de los derechos de todos y cada uno. La relación que establecen con el contexto y con la construcción de su propia identidad colectiva no es complaciente, sino dinámica y estratégica (Schlosberg 2004).

La acción política ciudadana invoca la soberanía popular en su asedio a las instituciones y en la generación de exclusas para resistir las intervenciones burocráticas. Desde esta práctica experimenta una creciente 
desconfianza hacia los responsables políticos de las mismas; reafirma el carácter segmentado, polifacético y reticular del movimiento; el acento puesto en el trabajo en red como una modalidad no reductible a una organización formal; la puesta en cuestión del conocimiento científico ante la identificación de sus compromisos bajo un manto de neutralidad, todas ellas prácticas que desafían las formas políticas dominantes.

Desde una fenomenología de la acción política ambientalista es posible afirmar que nos encontramos más en el terreno de las tácticas que de las estrategias, de la experimentación que de la continuidad de tradiciones existentes, de la autocrítica que del hablar profético en la construcción de lo que denominamos una Justicia Ambiental ${ }^{7}$. Las luchas ciudadanas se centran en identificar y resistir las relaciones de poder locales desde propuestas contra la colonización de los espacio vitales y también haciendo frente a los problemas a escala global de manera de converger en una movilización civil basada en una nueva concepción de la naturaleza y una democracia radical e igualitarista.

Tanto desde la elaboración de la filosofía política, como del saber intuitivo de las prácticas, la compatibilización entre estos compromisos es una tarea cotidiana, que no depende de la coherencia interna de una teoría, sino de las resoluciones parciales, históricas, contingentes de la acción democrática descentralizada en una esfera pública recreada constantemente.

\section{La centralidad de la esfera pública para la Soberanía Popular}

Frente a la indolencia y/o complicidad de las estructuras institucionales del estado, de los partidos políticos y hasta incluso de los sindicatos, y a la masividad de los problemas y los daños que producen, las acciones de la ciudadanía han llegado a tematizar los problemas en sus distintas dimensiones económicas, sociales, educativas, culturales, políticas, judiciales, entre otras (Carrizo y Berger 2012). Problemas que emergían como problemas locales, en torno a un foco de contaminación o destrucción del ambiente localizado, han llegado a ser articulados entre sí y a poder ser visualizados como problemas comunes de la totalidad de los habitantes actuales e incluso de las generaciones futuras.

Esta autocomprensión lograda en las luchas, ha llevado a que los conceptos también se vayan enriqueciendo y estructurando, para expresar la complejidad de las situaciones, de las aspiraciones y de las soluciones correspondientes. Es así que se ha invocado también y cada vez con mayor fuerza, el reclamo de autodeterminación tanto individual como colectiva -de los afectados y de los pueblos- en la determinación de las decisiones que afectan su vida y sus formas de vida (Lujan 2012). En esta línea es que consideramos un aporte los desarrollos contemporáneos de la teoría política respecto al concepto de Soberanía Popular, en tanto proporciona ele- 
mentos para comprender los desafíos de la acción política, tanto en el espacio público estatal como del espacio público ciudadano.

Reflexionado críticamente sobre el peso que han tenido los conceptos y las teorías en la historia política y social del siglo 20, y en el marco de los 200 años del ciclo revolucionario iniciado con la Revolución Francesa, Jürgen Habermas (1998) trabaja en la reconstrucción del concepto de Soberanía Popular despojándolo de sus componentes míticos y al mismo tiempo recuperándolo como clave para la continuidad de la revolución democrática.

Sintetizando, podemos señalar que un problema con el que se enfrenta la teoría política democrática es el peso y la fascinación que carga el concepto proveniente de la tradición medieval: la soberanía como el cuerpo del rey, absoluto, indiviso, perpetuo. Otro, no menos importante, es el trabajo de incorporar en su consideración los aprendizajes surgidos a partir de misma historia democrática. Como nos advierte Hannah Arendt, el impulso homogeneizante de la soberanía ha servido para destruir la multiplicidad constituyente, la propia pluralidad de la esfera pública, al imponer violentamente la peligrosa ficción de un macrosujeto unitario: el Pueblo como un todo. Tendría lugar así el ejercicio de una soberanía burocratizante y extractivista de los derechos de la ciudadanía, por empezar, del derecho a su participación política en y más allá del sistema oficial de autoridad. Una especie de administración de la población que se complejiza, pero no por procedimientos institucionales que garanticen derechos y la participación popular, sino por subordinar estos al mando estatal.

Atento a estos problemas, la reconstrucción del concepto que realiza Habermas concibe a la Soberanía Popular como una intersubjetividad descentrada, que se manifiesta bajo las condiciones discursivas de un proceso en sí mismo diferenciado de formación de opinión y voluntad. Trataremos primero, desarrollos que tienen que ver con la formación de opinión y posteriormente, desarrollos que tienen que ver con la voluntad, la toma de decisiones colectivas.

En la democracia como gobierno de la opinión, ocupa un lugar clave no sólo la decisión, sino también y específicamente la deliberación pública. El uso público de la razón, por parte de una ciudadanía informada, permite que las convicciones que se han desarrollado en el espíritu de distintos hombres actúen las unas sobre las otras; que se clarifiquen, que amplíen el círculo de su aceptación. La Soberanía Popular se constituye entonces como la instancia mediadora entre la razón y los procesos de toma de decisión colectiva institucionalizados en un Estado -que entonces es definido como - Democrático de Derecho, caso contrario, si sólo se sujeta a los procedimientos formales, estaríamos frente a un legalismo autoritario (Habermas, 1987).

En el modelo habermasiano, la Soberanía Popular es el poder generado en una red de comunicación libre, entre esferas públicas autónomas del sistema político. Es este poder el poder legítimo, que puede influir sobre las 
instituciones definiendo los temas, los problemas, los valores, los argumentos que serán aceptados como buenas razones.

El concepto de Soberanía Popular pierde su componente místico, se despersonaliza, se constituye intersubjetivamente, se dispersa en formas de comunicación que pueden disolver las premisas ideológicas establecidas en las instancias decisorias del sistema político, que obstaculizan las nuevas comprensiones de derechos y de los nuevos derechos surgidos de la acción política de la ciudadanía. Es desde este dinamismo que la Soberanía Popular continúa siendo la fuerza explosiva y configuradora de una sociedad democrática.

Su requisito es la existencia de una participación activa de la ciudadanía en una red de asociaciones que sostienen los fundamentos seculares de la política, la autodeterminación individual y pública y los derechos humanos. También sensible e inquieta a las situaciones problemáticas de la asociación política, generando un fluir de interpretaciones y enmarques capaces de resistir en la deliberación pública a los avances racionalizadores de la administración estatal y el mercado capitalista.

Es este carácter plural, público e igualitario, el que pugna por el Estado democrático constitucional como proyecto, como continuidad de la revolución democrática, con una interpelación permanente a la realización nunca acabada de sus exigentes fundamentos. El sentido normativo insito en estos presupuestos, lejos de prestar legitimidad al orden existente, promueve su permanente actualización acorde con la política de la ciudadanía, e incluso la desobediencia civil, cuando desde un legalismo autoritario se imponen decisiones que trasgreden los principios de justicia compartidos en los textos fundamentales.

\section{La Soberanía Popular y su institucionalización}

Nos interesa finalmente traer al debate sobre las posibilidades de institucionalización de la Soberanía Popular, los aportes de Hannah Arendt (1988). Vamos a detenernos en estos desarrollos en tanto consideramos que visualizarla como poder constituyente posibilita pensar la permanencia del poder que emerge de las luchas.

Comparando la Revolución Francesa con la Norteamericana, Arendt se diferencia de las lecturas típicas de las revoluciones, que hacen centro en la etapa inicial y violenta de la rebelión y la liberación, y se enfoca en lo que denomina segunda etapa, la de la revolución y de la constitución. A partir de ello critica a una teoría a la que califica de perjudicial, para la cual la Constitución deja de ser expresión del espíritu revolucionario y significa más bien la derrota o paralización de la revolución. Frente a esta teoría, sostiene que no hay nada más inútil que la rebelión y la liberación cuando no van seguidas de la constitución de la libertad recién conquistada. Para Arendt, lo significativo del acto constituyente es que es el acto por el que 
el pueblo constituye un gobierno y no viceversa, el acto por el cual se crea un nuevo poder, por lo que el término Constitución pierde su carácter negativo de limitación del poder.

La libertad política reside en el poder entendido como acción concertada, por lo que la esfera política debe constituirse de manera tal que liberad y poder se combinen. El problema, lejos de una visión liberal respecto a la limitación del poder, es la impotencia del poder político republicano, su destrucción por la violencia y los poderes fácticos, por lo que el aporte puede ser leído como un llamado de atención hacia la construcción de un diseño institucional que constituya un mecanismo generativo de poder popular.

Otra línea de recuperación de estos desarrollos que consideramos relevante desde nuestro contexto, tiene que ver con la visibilización de los factores que intervienen en la invención y consolidación del cuerpo político. En relación a la experiencia colectiva, el poder constituyente deviene de la estructura política preexistente. En la Revolución Norteamericana, el pueblo de las colonias estaba organizado por pactos preexistentes que los auto-constituían en "cuerpos políticos civiles", con suficiente poder para elaborar leyes e instrumentos de gobierno.

Los pactos eran pactos de co-asociación, alianzas, promesas, no eran pactos de cesión de derechos por los que los individuos manifestaban su consentimiento a ser gobernados, incluso las colonias habían elaborado sus propias constituciones. Los que participaron del poder constituyente federado eran delegados elegidos, por lo cual recibieron su poder del pueblo real, no ficcional. El poder de estos estados no se abolió con la constitución del cuerpo político, sino que fue sostenido por la promesa federal. En la gramática de la política de la autora la generación de encuentros, acuerdos, leyes en el espacio público actualiza la Soberanía Popular en el ejercicio del autogobierno.

\section{Para seguir pensando}

La reflexión sobre prácticas y conceptos propuesta desde las luchas en defensa del ambiente y los derechos aspira a llamar la atención sobre los supuestos que están sosteniendo las instituciones y las relaciones políticas vigentes. También a preguntarnos si es posible recuperar el sentido originario con el que surgieron o si debemos generar otros sentidos y otras instituciones. La posibilidad de una institucionalidad acorde con las aspiraciones de la Justicia Ambiental, nos exige reconocer la complejidad existente, definir con precisión y honestidad nuestros compromisos y fundamentalmente actuar con otros para hacerlos realidad.

Consideramos que la generación de redes de interacción autónomas, de organizaciones diversas y solidaridades entramadas desde el ejercicio de la autodeterminación, contribuyen a desafiar las formas dominan- 
tes de poder instituidas y definir y dar vigencia a nuevas instituciones que combinan tradiciones existentes y creatividad reflexiva de la acción política sobre las formas tradicionales, apostando al aprendizaje político colectivo, la experimentación y la democracia.

En este sentido cooperamos con la reconsideración de los conceptos de ciudadanía y soberanía popular como ejes de la configuración institucional de una república. Entendemos que los flujos comunicativos que avanzan en la construcción de una estructura política defensiva del ambiente y los derechos, pueden recuperar el lenguaje de los derechos en tanto medio de reconocimiento de la pluralidad y de resolución de conflictos en una sociedad compleja, avanzando en la recreación de la democracia. 


\section{Notas}

${ }^{1}$ El presente artículo se basa en las actividades del proyecto Institucionalidad Democrática y Derechos Colectivos. Experiencias provinciales comparadas en Argentina. Cuenta con el apoyo de la Secretaría de Ciencia y Técnica de la Universidad Nacional de Córdoba.

${ }^{2}$ El derecho ambiental denomina presupuestos mínimos a estándares de regulación y control que se fijan para todo un territorio, pudiendo las jurisdicciones locales regular por encima de ellos de manera más restrictiva.

${ }^{3}$ Un problema nuevo es el intento de reducir el reconocimiento de legitimidad procesal para la defensa de derechos colectivos e intereses difusos que tiene lugar en la actualidad. Tal el caso del actual proyecto de reforma del Código Civil y Comercial de Argentina que revierte un proceso de ampliación de la legitimidad para la presentación de amparos de años y con importante jurisprudencia.

${ }^{4}$ http://www.opsur.org.ar/blog/2012/04/03/convocatoria-nacional-al-parlamento-delos-pueblos-tucuman-19-y-20-de-abril/

${ }^{5}$ http://www.noalamina.org/mineria-latinoamerica/mineria-general/conclusiones-segundo-parlamento-medioambiental-patagonia-2

6 “Artículo 3: Los Gobiernos Contratantes convienen en que los límites de los parques nacionales no serán alterados ni enajenada parte alguna de ellos sino por acción de la autoridad legislativa competente. Las riquezas existentes en ellos no se explotarán con fines comerciales"

${ }^{7}$ El concepto refiere para nosotros a una pluralidad de prácticas en el espacio público estatal y no estatal desde situaciones de injusticia hacia la transformación del sentido de justicia. En ello, formamos parte de quienes están tratando de ampliar la conceptualización que de la Justicia Ambiental que la restringe a la denuncia de la desigual distribución del daño ambiental hacia grupos por su condición de clase, raza y género, uso más extendido en el activismo y la academia (Di Chiro 1999). 


\section{Bibliografía}

Acselrad, Henri (2010), “Ambientalizacao das lutas ambientais. O caso do movimento de justica ambiental no Brasil”. Revista Estudos Avancados. Vol.24 No.68, São Paulo.

Ídem (2012), “Descaminhos do “ambientalismo consensualista”, en Movimientos socioambientales en América Latina. Revista del OSAL N 32.

Arendt, Hannah (1988), Sobre la revolución. Alianza. Madrid.

Arnulphi, Cristina (2012), “Asambleas ciudadanas contra la contaminación y el saqueo de la movilización hasta la legislación”, en Carrizo, C. y Berger, M., Justicia Ambiental y Creatividad Democrática. Alción Editora, Córdoba.

Berger, Mauricio (2012), “Redes de Justicia Ambiental en América Latina: entre la creatividad democrática y las nuevas instituciones de lo común”, en Carrizo, C. y Berger, M., Justicia Ambiental y Creatividad Democrática. Alción Editora, Córdoba.

Carrizo, Cecilia (2010), "La narrativa de los derechos: de la administración de la población a la construcción de la república”, en La Serna C., Peón, C., Ase I. (Compiladores) Frente a la crisis, ¿Qué hacer con el Estado? UNCIIFAP-SAAP, Córdoba.

Ídem (2011), Ley de Bosques Nativos. Instituciones y prácticas para la efectiva garantía del derecho a la vida y al ambiente. Mimeo.

Ídem (2012), “Una lectura del Fallo Horne desde la Justicia Ambiental”, en Carrizo, C. y Berger, Mauricio, Justicia Ambiental y Creatividad Democrática. Alción Editora, Córdoba.

Idem (2012), “La Soberanía Popular y la Justicia Ambiental”, en Carrizo, C. y Berger, M., Justicia Ambiental y Creatividad Democrática. Alción Editora, Córdoba.

Carrizo, Cecilia y Berger, Mauricio (2009), Estado incivil y ciudadanos sin estado. Paradojas del ejercicio de derechos en cuestiones ambientales. Narvaja Editor, Córdoba.

Ciuffolini, Alejandra (Comp.) (2012), Por el oro y el moro. Explotación minera y resistencias en Catamarca, Córdoba y La Rioja. Obra editada por el colectivo de investigación El llano en llamas. UCC, Córdoba.

Di Chiro, Giovanna (1999), "La justicia social y la justicia ambiental en Estados Unidos. La naturaleza como comunidad”, en Goldman, M, Privatizing Nature. Political Struggles for the Global Commons. Pluto Press y Transnational Institute, Londres. 
Ferrajoli, Luigi (2001), Derecho y Razón. Trotta, Madrid.

Fraser, Nancy (2005), “Reinventar la justicia en un mundo globalizado”. New Left Review 36.

Idem (2008), Escalas de justicia. Herder, Barcelona.

Fraser, Nancy y Axel Honneth (2006), ¿Redistribución o reconocimiento? Un debate político-filosófico. Madrid, Morata.

Habermas, J. (1987), “Desobediencia civil piedra de toque del estado democrático de derecho”, en Ensayos políticos. Península, Barcelona.

Idem (1998), “La soberanía popular como procedimiento”, en Facticidad y Validez. Sobre el derecho y el estado democrático de derecho en términos de la teoría del discurso. Trotta, Madrid.

Hervé Espejo, Dominique (2010), “Noción y elementos de la Justicia Ambiental: directrices para su aplicación en la planificación territorial y en la evaluación ambiental estratégica”, en Revista de Derecho vol. XX Nº1.

Lujan, Jenny (2012) “Construcción de redes provinciales, regionales, nacionales y transnacionales contra la Mega-minería. Logros y dificultades” en Carrizo, Cecilia y Berger, Mauricio (comp.) Justicia Ambiental y Creatividad. Alción Editora, Córdoba.

Machado, Horacio (2012), Catamarca “Minera-lizada”: la represión como "política de Estado" y la rearticulación de un nuevo régimen de violencia colonial. http://www.noalamina.org/mineria-argentina/mineria-catamarca/ catamarca-minera-lizada. Fecha de acceso 10 de abril de 2013.

Manessi, Carlos (2012) “El Movimiento de los Pueblos Fumigados de la Provincia de Santa Fe. Avances y logros”, en Carrizo, Cecilia y Berger, Mauricio (comp.) Justicia Ambiental y Creatividad. Alción Editora, Córdoba.

Martínez Allier, Joan (1994), De la economía ecológica al ecologismo popular. Icaria, Barcelona.

O’Connor, Martín (1994), “El mercadeo de la naturaleza. Sobre los infortunios de la naturaleza capitalista”, en Ecologia Política N ${ }^{a}$ 7. Icaria, Barcelona.

Putman, Hilary y Habermas, Jûrgen (2008), Normas y Valores. Editorial Trotta, Madrid.

Red Brasilera en Justicia Ambiental: http://www.justicaambiental.org.br

Red de Justicia Ambiental en Chile: http://www.olca.cl 
Schlosberg, D. (2004), "Reconceiving Environmental Justice: Global Movements and Political Theories”, en Environmental Justice Politics, Vol. 13, No.3.

Ídem (2011), “Justicia Ambiental y Climática: de la equidad al funcionamiento comunitario”, en Revista Ecología Política, № 41.

Sede, Soledad (2012) “Una experiencia de creación de redes. La conformación de la Red de Asistencia Jurídica contra la Mega- Minería (REDAJ)”, en Carrizo, Cecilia y Berger, Mauricio (comp.) Justicia Ambiental y Creatividad. Alción Editora, Córdoba.

Sodero Nievas, Victor (2012) "HORNE, SILVIA RENEE S/ ACCION DE AMPARO (ART. 43 C.PCIAL)”. en Carrizo, Cecilia y Berger, Mauricio (comp.) Justicia Ambiental y Creatividad. Alción Editora, Córdoba.

Sunstein, Cas (2006), Riesgo y Razón. Seguridad, ley y Medio Ambiente. Katz Editores. Bs. As.

Tomasoni, Marcos (2012) “De la urgencia local a la organización de una demanda provincial. La construcción del Paren de Fumigar Córdoba”, en Carrizo, Cecilia y Berger, Mauricio (comp.) Justicia Ambiental y Creatividad. Alción Editora, Córdoba.

Valdivieso, Joaquin (2005), “La globalización del ecologismo. Del egocentrismo a la justicia ambiental de Joaquín Valdivieso", en Medio Ambiente y Comportamiento Humano.

Zeballos, M.C. (2000), “Hacia la creación de un Sistema Jurídico Ambiental en la Argentina”, en Instituto de Política Ambiental. Tercera Jornada de Reflexión sobre Temas Ambientales. Córdoba.

Web de la Unión de Asambleas Argentinas: http:// www.asambleasciudadanas.org.ar/ http://twitter.com/prensauac 